\title{
Design da Informação e Inovação: a experiência do Governo de Santa Catarina no Combate à COVID-19
}

\author{
Jefferson L. Velasco, Helouíse H. G. Viola, Israel A. Braglia, Júlio M. Teixeira
}

\begin{abstract}
Resumo
A partir do ano de 2020 diferentes autoridades administrativas e governamentais precisaram traçar estratégias de combate à COVID-19 a nível local e global. Um dos meios para lidar com estes desafios relaciona-se à produção e gerenciamento de dados para monitorar indicadores epidemiológicos dando suporte à tomada de decisão e transparência à sociedade. Diante desse contexto, este artigo apresenta um estudo de caso aplicado ao ambiente de inteligência de dados do Governo do Estado de Santa Catarina para o combate à COVID-19, aplicando o método de Garrett (2011) na estruturação de dados para visualização de informações relevantes. Como procedimentos metodológicos adaptou-se o modelo de planos de elementos proposto pelo autor, que foi aplicado ao processo estruturação de dados. Desta forma foi possível constatar a adequação do modelo proposto, pela facilidade, acessibilidade, comunicação e organização dos dados e informações disponibilizadas nos painéis construídos.
\end{abstract}

\section{Abstract}

As of 2020, different administrative and governmental authorities needed to devise strategies to fight COVID-19 in both local and global levels. One of the strategies to deal with those challenges is related to the production and management of data to monitor epidemiological indicators, supporting decision making and transparency to society. Given this context, this article presents a case study applied to the data intelligence environment of the Government of the State of Santa Catarina to fight COVID-19, applying the Garrett's (2011) method for structuring data to present relevant information. As methodological procedures, the element plans model proposed by the author was adapted, which was applied to the data structuring process. In this way, it was possible to verify the adequacy of the proposed model, due to the ease, accessibility, communication and organization of data and information made available at the constructed dashboards.

\section{Introdução}

Em março de 2020 o mundo se deparou com um evento epidêmico de proporções globais. Em poucos meses, autoridades sanitárias e administrativas foram forçadas a traçar estratégias de combate à COVID-19 em nível local. Para enfrentar estes desafios, seria necessário produzir dados que permitissem o acompanhamento de indicadores epidemiológicos, além de permitir a gestão de recursos na área de saúde pública e servir de suporte à tomada de decisões e de atender às demandas de transparência da sociedade.

Neste sentido, Christensen e Lægreid (2020), citam duas questões importantes na atuação governamental em crises sociais e seu gerenciamento: 1. capacidade de governança para

Anais do $10^{\circ} \mathrm{CIDI}$ e $10^{\circ} \mathrm{CONGIC}$

Kelli C.A.S. Smythe, Rafael de Castro Andrade (orgs.)

Sociedade Brasileira de Design da Informação - SBDI

Curitiba | Brasil | 2021
Proceedings of the $10^{\text {th }} \mathrm{CIDI}$ and $10^{\text {th }}$ CONGIC

Kelli C.A.S. Smythe, Rafael de Castro Andrade (orgs.)

Sociedade Brasileira de Design da Informação - SBDI Curitiba | Brazil | 2021 
prover um gerenciamento efetivo da crise; e 2. legitimidade a fim de manter a adesão popular às medidas de enfrentamento (Lægreid \& Rykkja, 2018).

Enquanto a primeira se relaciona à capacidade de compreender e analisar o cenário, coordenar ações, regular limites sociais e entregar soluções, a segunda se relaciona à construção de uma relação de confiança com a população, à prestação de contas de suas ações e gastos, à criação e atendimento de expectativas e obtenção de apoio popular.

Ambas as questões demandam uso de dados para que as respostas do gestor público sejam adequadas. Se uma governança eficiente depende do conhecimento do gestor público sobre os fatos (Duan et al., 2020), a legitimidade depende do grau de transparência das ações governamentais pois, na medida em que dados e ferramentas tecnológicas propiciam avanços na democracia participativa (Colombo, 2016), também aumentam as exigências sobre a qualidade destas informações.

A disponibilização de dados para análise requer a atuação do design da informação (Jorente, 2015) a fim de tornar mais fácil a sua compreensão e a subsequente construção de conhecimento. Porém a disciplina do design da informação pouco se ocupa dos processos de estruturação de dados, mantendo seu foco no planejamento e construção das camadas de visualização da informação e artefatos gráficos.

Esta constatação leva ao seguinte questionamento: de que forma o design da informação pode atuar na construção de processos de estruturação de dados para visualização de informações relevantes, no contexto do combate à COVID-19?

Para responder a esta pergunta, foi realizado um estudo de caso a partir do modelo de elementos proposto por Garrett (2010) aplicado à construção do ecossistema de inteligência de dados do Governo do Estado de Santa Catarina para o combate à COVID-19.

\section{Design da Informação e Estruturação de Dados}

Para Petterson (2003) o design da informação compreende a análise, planejamento, apresentação e compreensão de uma mensagem e seu conteúdo, incluindo linguagem e forma, satisfazendo requisitos de estética, economia, ergonomia e matéria.

Jorente (2015) propõe a ocorrência do design da informação em ambientes que buscam levar seus objetivos informacionais de forma visual de acordo com público-alvo, processos e resultados esperados. Para a autora, a organização de dados e informações é um processo que busca reconhecer sentido no conteúdo, sintetizando dados em informação relevante.

Em uma abordagem mais simples, Katz (2012) explica que os dados, o designer e a audiência são aspectos fundamentais para o design da informação. Neste sentido, Teixeira (2019) afirma que informação é criada a partir de dados representados de forma visual que passam por processos de transformação, Ihes atribuindo contexto para facilitar a compreensão.

Desta forma, o dado se configura como um elemento importante do design da informação, mas a disciplina pouco se preocupa com a sua estruturação e a influência deste processo na visualização da informação. Publicações sobre estruturação de dados aparecem com 
frequência nas áreas de ciência da informação ou tecnologia da informação, focados em seus aspectos técnicos, enquanto a literatura do design se limita a tratar mais objetivamente dos aspectos visuais de sua representação.

Este trabalho se ocupa da redução dessa lacuna, propondo uma interação direta entre o design da informação e a estruturação dos dados para a entrega de informação visual relevante.

\section{Método de Garrett}

O avanço no uso de tecnologias de informação, sobretudo nas áreas de big data e business intelligence (Darós et al., 2005), têm influenciado a entrega de produtos de dados na esfera governamental. Marcados por aspectos interdisciplinares, estes projetos se beneficiam de conhecimentos das áreas das ciências cognitivas, gestão, engenharia de software, design, dentre outras, na medida em que os problemas abordados se localizam em diferentes dimensões da administração pública, objetivando a entrega de uma experiência mais produtiva e centrada nos usuários.

Garrett (2011) aborda o tema, propondo um método baseado em cinco elementos essenciais da a experiência do usuário, organizados em planos: estratégia, escopo, estrutura, esqueleto e superfície. Embora seu trabalho seja orientado ao desenvolvimento de experiências voltadas à websites, os conceitos podem ser adaptados para tecnologias e processos mais complexos.

De acordo com o autor, cada plano pode ser observado a partir de duas perspectivas: funcionalidade e informação. Esta pesquisa se concentra nos aspectos relacionados à informação e se utiliza do modelo para a construção de processos de estruturação de dados para visualização. Os elementos são distribuídos no modelo partindo do plano mais abstrato para o mais concreto, conforme descrição a seguir: 
Figura 1: Planos de Elementos de Experiência (Garret 2011). Fonte: The Elements of User Experience: user centered design for the web and beyond (Garrett, 2011)

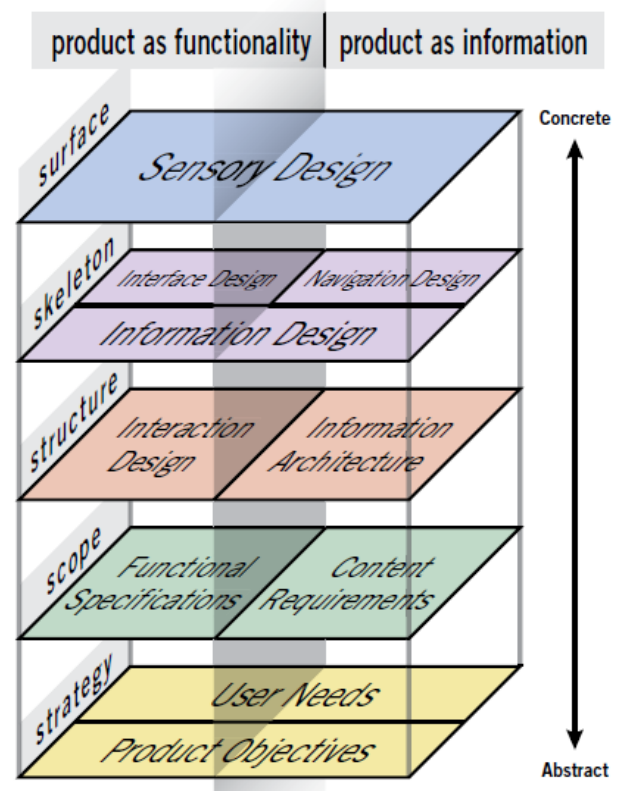

Plano Estratégico: especifica as necessidades dos usuários e os objetivos do produto. Os dois elementos podem ser descritos a partir do foco em funcionalidade ou informação. Este é o plano mais abstrato do modelo.

Plano de Escopo: define as especificações funcionais do projeto e os requisitos de conteúdo. A estratégia estabelecida no plano anterior se transforma em um escopo bem definido, na forma de requisitos do projeto (features) a serem implementados.

Plano Estrutural: focado no design da interação e na arquitetura da informação. Arquitetura da informação é normalmente caracterizada pelo arranjo dos elementos de conteúdo para melhor compreensão, em consonância com os processos cognitivos dos usuários. Neste estudo, a arquitetura da informação se relaciona com a construção de datasets centralizadores capazes de fornecer os elementos para atender aos requisitos definidos nos planos anteriores.

Plano de Esqueleto: composto pelo design da interface (funcionalidade), pelo design de navegação (informação) e pelo o design da informação. Relaciona-se, neste estudo, com a produção de datasets especializados (a partir dos centralizadores), capazes de responder questionamentos específicos formulados pelos usuários.

Plano de Superfície: neste plano, tanto do ponto de vista da funcionalidade quanto da informação, o foco é a experiência sensorial. Trata-se da entrega dos produtos finais, neste caso, compostos principalmente de painéis de BI e datasets de dados abertos. É o plano mais concreto do modelo. 


\section{Procedimentos Metodológicos}

A pesquisa classifica-se como aplicada, pois, objetiva gerar conhecimentos para aplicações práticas dirigidos à solução de problemas específicos (Gil, 1994). Possui abordagem qualitativa por permitir uma compreensão mais profunda de determinados fenômenos e não utilizar dados estatísticos como foco principal de sua análise (Haguete, 1995), além de admitir a análise de percepções a fim de compreender melhor os fenômenos sociais que ocorrem na situação foco de estudo (Collins \& Hussey, 2005).

Quanto aos seus objetivos, possui caráter exploratório, devido a intenção de conhecer melhor determinado assunto ainda pouco explorado (Richardson, 2015) e caráter descritivo devido a intenção de descrever as características do problema apontado (Richardson, 2015). Por fim, trata-se de um estudo de caso que diz respeito, conforme Calanzas (2007, p.39), a " uma estratégia de pesquisa utilizada para investigar um fenômeno social complexo".

No que se refere ao procedimento metodológico, a pesquisa adapta os planos de elementos de Garret (2011), apresentados no item anterior, para aplicação na construção de processos de estruturação de dados para visualização da informação. Para isso, primeiramente foi realizado um diagnóstico dos atores envolvidos nos processos de estruturação de dados, em seguida, foi identificado e relacionado cada plano de elementos de Garret (2011) a cada etapa do processo de estruturação de dados, chegando então à aplicação prática da adaptação proposta, sobre a qual se discorre a seguir.

Os artefatos gráficos (que não são objetos deste estudo) foram desenvolvidos a partir das visões de dados criadas de acordo com o método em foco, utilizando-se a ferramenta Microsoft Power BI. Outros detalhes pertinentes ao estudo são apresentados no item "análise dos resultados".

\section{Análise dos Resultados}

A pesquisa foi pautada pela estruturação dos dados para a produção de informação relevante em um ambiente de inteligência de dados para o combate à COVID-19. Neste sentido, a quantidade e a diversidade de fontes de dados envolvidas revelaram-se fatores de complexidade para o projeto, demandando uma estratégia ampla de catalogação, captura, estruturação e entrega de dados. A figura a seguir representa o fluxo de dados considerando os atores envolvidos, os dados produzidos, as fontes de consulta, o repositório técnico do dado (onde ocorrem as transformações) e as entregas esperadas: 
Figura 2: Fluxo de dados. Fonte: os autores

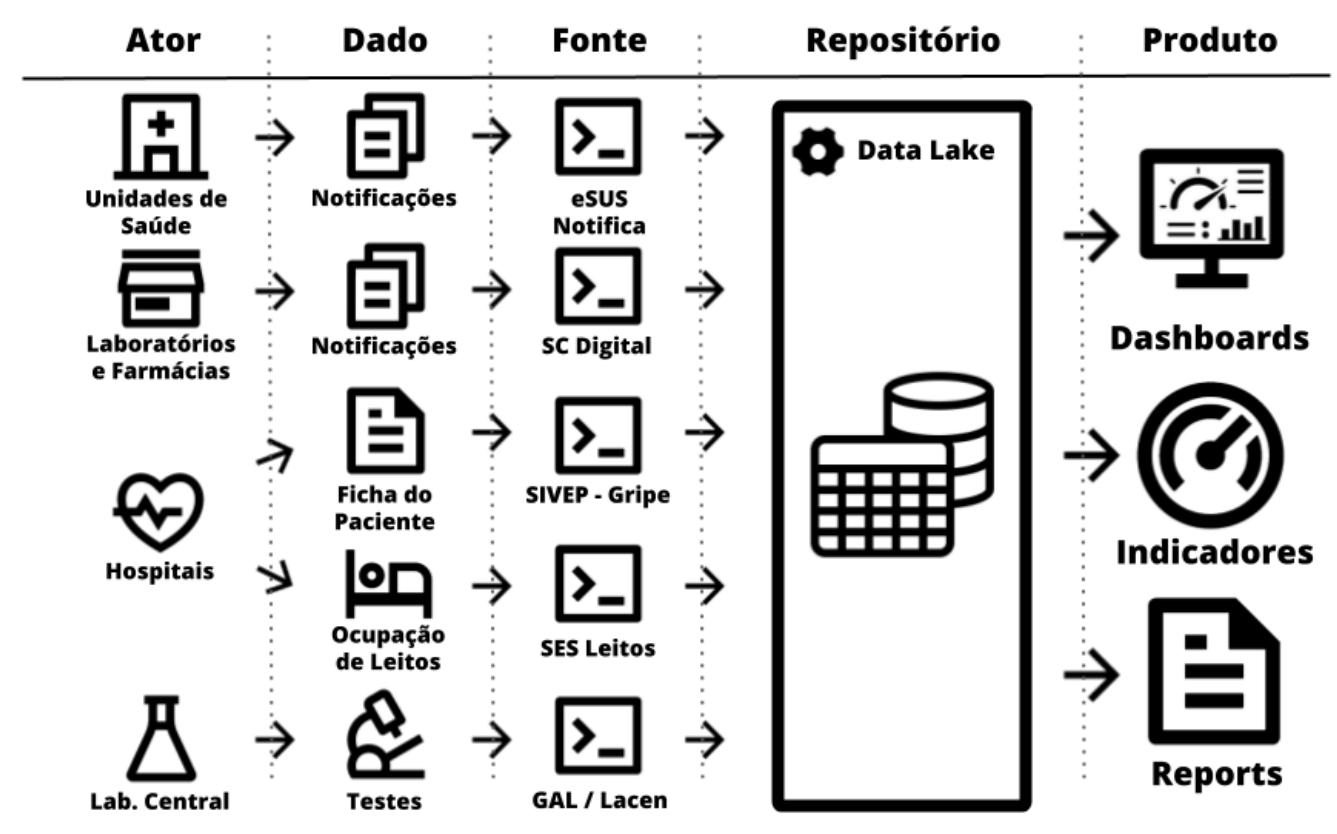

Métodos e procedimentos da ciência de dados (tecnologia da informação), de design de interfaces e design da informação visual também foram amplamente utilizados, mas não são o foco deste trabalho. Salienta-se, no entanto, que a informação fundamental sobre a qual os dados foram estruturados é a notificação de um caso positivo em qualquer uma das fontes utilizadas. Para estabelecer relações entre as fontes foram utilizadas informações de identificação pessoal, tais como o número do Cadastro de Pessoa Física (CPF) do paciente ou, na ausência desse, uma chave forte composta de nome completo, data de nascimento e nome da mãe do paciente. Estas integrações, inexistentes nas fontes de origem, foram construídas posteriormente, dentro do ambiente do data lake do Governo do Estado de Santa Catarina.

Os resultados serão descritos de acordo com sua relação com os planos do modelo de elementos de Garrett (2011), adaptado para a estruturação de dados para o design da informação.

\section{Centro de Informática e Automação do Estado de Santa Catarina}

O Centro de Informática e Automação do Estado de Santa Catarina S.A. (CIASC) é uma empresa de economia mista que executa serviços de processamento de dados, tratamento de informações e assessoramento técnico em informática para os órgãos da administração, direta e indireta, do governo do Estado de Santa Catarina (Barros, 2004).

Entre os sistemas administrados pela empresa está a Plataforma BoaVista, data lake oficial do governo que reúne dados de diversas secretarias, entre elas a Secretaria de Estado da Saúde (SES) responsável pelos dados relacionados à COVID-19.A Plataforma BoaVista é composta por duas camadas bem definidas: 
- BoaVista Dados: ecossistema de big data que consiste em um framework para o processamento de grandes quantidades de dados (Goldman et al., 2012). A plataforma BoaVista Dados é o data lake do Governo do Estado de Santa Catarina;

- BoaVista Gestão: uma aplicação desenvolvida pelo CIASC para a integração de painéis de business intelligence $(\mathrm{BI})$ e outras aplicações gerenciais ou operacionais.

Os procedimentos descritos a seguir foram implementados através de integrações de dados centralizados no BoaVista Dados, cujos resultados foram consolidados em tabelas e visões, representados em painéis de BI e disponibilizados através da plataforma BoaVista Gestão ou no site http://www.coronavirus.sc.gov.br/ onde podem ser acessados publicamente navegandose pelos itens de menu "transparência" e, em seguida, "painéis".

\section{Aplicação da Adaptação do Plano de Elementos de Experiência de Garrett (2011)}

O processo de estruturação de dados foi adequado ao plano de elementos proposto pelo autor visando a facilitação do processo de design da informação no produto.

Partiu-se da premissa de seria mais fácil, rápido e assertivo construir a representação visual de uma informação a partir de um dataset construído levando-se em conta os resultados desejados para sua representação, motivados pela complexidade das fontes de dados envolvidas.

Além disso, verificou-se que alguns objetivos definidos nos planos estratégico e de escopo, não poderiam ser atingidos sem um processo de estruturação que permitisse a consolidação dos dados integrados e sua subsequente organização em visões especializadas.

A figura a seguir apresenta o detalhamento das ações de estruturação de dados do projeto em consonância com o modelo:

Figura 3: Adaptação dos Planos de Elementos de Experiência de Garrett (2011). Fonte: os autores

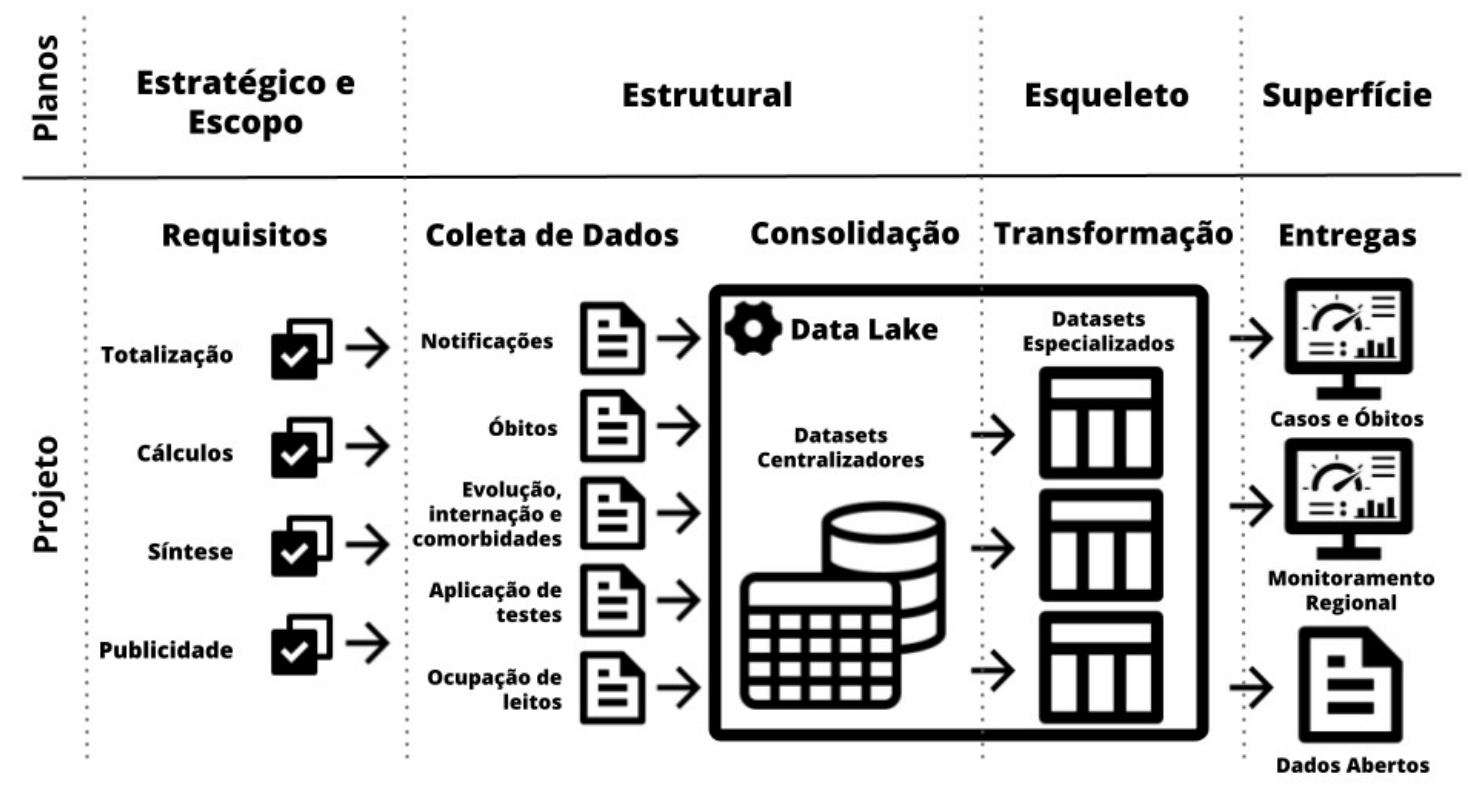




\section{Planos Estratégico e de Escopo}

No plano estratégico foram mapeadas as necessidades dos usuários e os objetivos do produto. Dada a urgência por resultados, as duas etapas foram condensadas em um processo mais ágil, que resultou em uma lista de requisitos do projeto. Aqui estão apresentados apenas os requisitos relacionados ao objeto deste estudo, agrupados por categoria:

- Totalização: casos confirmados; casos ativos, óbitos; testes aplicados (RT-PCR e Rápidos); testes aguardando liberação (RT-PCR); e testes rápidos distribuídos.

- Cálculos: taxa de letalidade; incidência de comorbidades; variação semanal de casos confirmados; percentuais de exames positivos, negativos e inconclusivos; taxa de positividade nos últimos 7 dias (rede pública e privada); projeção de casos infectantes; indicadores para matrizes de risco e ocupação de leitos.

- Síntese: sintetizar a informação por município, macrorregiões e regiões de saúde ${ }^{1}$

- Publicidade: dar publicidade a estas informações na forma de painéis de BI e datasets de dados abertos anonimizados.

Cabe apontar que as taxas de ocupação de leitos são calculadas por outra equipe e, portanto, fora do escopo desta pesquisa. Entretanto, os datasets centralizadores e de dados abertos indicam a ocupação de leito por caso individual, especificando caso seja uso de leito de UTI.

\section{Plano de Estrutura}

Esta etapa foi focada na definição de uma arquitetura da informação, passando pela identificação de fontes de dados e o planejamento da sua coleta e consolidação em datasets centralizadores.

As principais fontes de dados são o sistema eSUS Notifica, plataforma do Governo Federal onde são feitas as notificações obrigatórias de doenças infecto-contagiosas e agravos definidos na Portaria $N^{\circ} 264$, de 17 de fevereiro de 2020, onde se define a Lista Nacional de Notificação Compulsória de Doenças, Agravos e Eventos de Saúde Pública (Anexo V), e o sistema SC Digital, onde laboratórios privados e farmácias podem submeter suas notificações em lote ou formulário.

Os dados cadastrados pelas unidades de saúde no eSUS Notifica são enviados diretamente ao Governo Federal para depois serem capturados por meio de webservices e armazenados no data lake do estado. Em ambos os casos, o foco são as notificações de casos confirmados de COVID-19, dado que forma a base estrutural da arquitetura de dados.

A tabela a seguir relaciona as fontes de dados identificadas, sua esfera de manutenção e os dados de interesse:

\footnotetext{
${ }^{1}$ O estado de Santa Catarina é dividido em macrorregiões administrativas e regiões de saúde, que são agrupamentos de municípios por diferentes critérios de conveniência.

${ }^{2}$ Síndromes Respiratórias Agudas Graves.
} 
Tabela 1: Fontes de Dados

\begin{tabular}{|c|c|c|}
\hline Fonte & Esfera & Dado \\
\hline eSUS Notifica & Federal & Notificações de casos confirmados na rede pública; \\
\hline SC Digital & Estadual & $\begin{array}{l}\text { Notificações de casos confirmados na rede privada (laboratórios e } \\
\text { farmácias); }\end{array}$ \\
\hline SIVEP Gripe & Federal & $\begin{array}{l}\text { Notificações de SRAGs e evolução de casos confirmados, } \\
\text { internações, comorbidades, etc.; }\end{array}$ \\
\hline SES Leitos & Estadual & Ocupação de leitos (Enfermaria e UTI); \\
\hline GAL/Lacen & Federal & Distribuição de testes RT-PCR e testes rápidos; \\
\hline SIM Datasus & Federal & Evolução para óbito. \\
\hline
\end{tabular}

A lógica da operação, pautada pela menor granularidade do dado, é orientada pela identificação de um caso confirmado de COVID-19 através de um exame laboratorial ou clínico, capturado em uma das fontes oficiais onde são cadastradas as fichas dos pacientes da rede pública ou privada (eSUS Notifica e SC Digital) junto com os dados de identificação do paciente, dados demográficos e do exame realizado, como data, tipo de teste, município onde foi realizado etc.

Os processos de transformação adicionam à informação inicial outros dados, como a evolução para recuperação, internação, internação em UTI ou óbito, comorbidades, indicação de gestante e georreferenciamento. A granularidade definida na menor unidade possível permite que as análises entreguem respostas para os questionamentos dentro de cada categoria de requisitos usando regras de negócio e funções matemáticas simples (como cálculo de taxas de letalidade ou a totalização de casos ativos) ou cálculos estatísticos mais complexos como a projeção de casos infectantes (Wang et al., 2020). Estas atividades de análise e planejamento (Petterson, 2003) permitem a representação gráfica do dado no artefato. Se não fossem realizadas, o designer não seria capaz de atender, por exemplo, ao requisito do cálculo de casos infectantes.

\section{Plano de Esqueleto}

Para que requisitos específicos sejam atendidos, datasets especializados são construídos a partir dos datasets centralizadores. Estes datasets são coleções de dados criadas a partir de operações de transformação, concentrando informações diretamente relacionadas aos requisitos do projeto. Para Jorente (2015) este processo representa a organização de dados que atribuem sentido em seu conteúdo, os sintetizando em informação relevante.

Além dos requisitos nascidos das necessidades dos usuários e dos objetivos do produto, outros requisitos foram identificados ao longo do tempo, como aqueles relacionados à auditoria de processos e tratamento de duplicidades de casos confirmados, já que um exame pode ser

\footnotetext{
${ }^{2}$ Síndromes Respiratórias Agudas Graves.
} 
reportado em diferentes fontes (sistemas) ou um paciente pode realizar diferentes exames, agregando ainda complicadores como erros de grafia e digitação.

Tabela 2: Datasets especializados

\begin{tabular}{ll}
\hline Contexto & Descrição \\
\hline Dados anonimizados & $\begin{array}{l}\text { Dados anonimizados com informações individuais de cada caso e com } \\
\text { atualização do quadro de cada caso conforme a evolução; }\end{array}$ \\
Nowcasting/Infectantes & $\begin{array}{l}\text { Dados para alimentação de algoritmo em R³ para cálculo de tendência de } \\
\text { prevalência e mortalidade da COVID-19 usando indicador avançado } \alpha-\end{array}$ \\
& Sutte (WANG et al., 2020); \\
Matrizes de Risco & $\begin{array}{l}\text { Dados sumarizados para alimentação dos sistemas que calculam } \\
\text { indicadores de risco epidemiológico que indicam o nível de risco de cada } \\
\text { região do estado; }\end{array}$ \\
Mapa de Situação & $\begin{array}{l}\text { Dados de casos ativos e óbitos geolocalizados para plotagem da } \\
\text { informação em aplicações de georreferenciamento; }\end{array}$ \\
Séries Históricas/Auditoria & $\begin{array}{l}\text { Dados que mantém o histórico das cargas diárias para fins de } \\
\text { acompanhamento das séries históricas e auditoria dos processos; }\end{array}$ \\
Duplicidades & Dados de possíveis duplicidades para tratamento na origem do cadastro; \\
Dados para Municípios & $\begin{array}{l}\text { Dados não anonimizados destinados a consulta de possíveis } \\
\text { disparidades entre as informações do governo estadual e dos municípios } \\
\text { para fins de conferência e correção nas fontes de cadastro; }\end{array}$ \\
\hline
\end{tabular}

A criação de datasets especializados é feita para o atendimento de requisitos específicos e com a participação ativa das equipes responsáveis pelo design de painéis.

Isso garante que não existam limites impostos ao designer para representação gráfica de indicadores ou informações por falta de dados. Além disso, a estratégia otimiza processos de leitura de dados pelas ferramentas de BI tornando os processos de atualização e desenvolvimento dos painéis mais rápidos.

Desta forma, o esqueleto montado para a composição da informação resolve questões operacionais e funcionais, simplificando o processo de desenvolvimento. A finalidade, no entanto, é garantir que a informação esteja validada, organizada e pronta para a composição das representações visuais em consonância com Jorente (2015).

Aguilar (apud Teixeira, 2018) explica que somos capazes de assimilar grandes quantidades de dados sem muito esforço usando recursos visuais. Porém estes são limitados pelas possibilidades oferecidas pela arquitetura de dados apresentada ao desenvolvedor do artefato. A montagem do esqueleto, a partir da estruturação, resolve estas limitações.

\footnotetext{
${ }^{3}$ https://www.r-project.org/about.html
} 


\section{Plano de Superfície}

Os resultados do projeto podem ser observados nos painéis de dados públicos disponibilizados pelo Governo de Santa Catarina no site oficial de combate ao coronavírus no estado, bem como no portal de dados abertos do governo.

As principais entregas do projeto, relacionadas aos requisitos estabelecidos nos planos estratégico e de escopo, estão listadas na tabela a seguir:

Tabela 3: Entregas vs. Requisitos

\begin{tabular}{|c|c|c|}
\hline Entrega & Categoria & Requisito(s) atendido(s) \\
\hline $\begin{array}{l}\text { Conjunto de Dados Abertos } \\
\text { de Casos Confirmados }\end{array}$ & Publicidade & $\begin{array}{l}\text { Dar publicidade às informações na forma de dados } \\
\text { abertos anonimizados }\end{array}$ \\
\hline \multirow[t]{7}{*}{ Painel de Casos e Óbitos } & Publicidade & Dar publicidade às informações na forma painéis de BI \\
\hline & Totalização & Casos confirmados; casos ativos, óbitos; testes \\
\hline & & aplicados (RT-PCR e Rápidos); testes \\
\hline & & aguardando liberação (RT-PCR); e testes \\
\hline & & rápidos distribuídos \\
\hline & Cálculos & $\begin{array}{l}\text { Taxa de letalidade; incidência de comorbidades; } \\
\text { variação semanal de casos confirmados }\end{array}$ \\
\hline & Síntese & $\begin{array}{l}\text { Sintetizar a informação por município, macrorregiões e } \\
\text { regiões de saúde }\end{array}$ \\
\hline \multirow{3}{*}{$\begin{array}{l}\text { Painel de Monitoramento } \\
\text { Regional }\end{array}$} & Publicidade & Dar publicidade às informações na forma painéis de BI \\
\hline & Cálculos & $\begin{array}{l}\text { Percentuais de exames positivos, negativos e } \\
\text { inconclusivos; taxa de positividade nos últimos } 7 \text { dias } \\
\text { (rede pública e privada); projeção de casos } \\
\text { infectantes; indicadores para matrizes de risco }\end{array}$ \\
\hline & Síntese & $\begin{array}{l}\text { Sintetizar a informação por município, macrorregiões e } \\
\text { regiões de saúde }\end{array}$ \\
\hline
\end{tabular}

O atendimento dos requisitos foi concentrado em três grandes entregas: 1. Conjunto de Dados Abertos de Casos Confirmados ${ }^{4}$; 2. Painel de Casos e Óbitos; e 3. Painel de Monitoramento Regional ${ }^{5}$.

Vale ressaltar que, embora este estudo esteja focado nas entregas de caráter público como estudo de caso para descrever a aplicabilidade do modelo de elementos de Garrett, o projeto como um todo alcança outras necessidades, requisitos e entregas usadas como apoio

\footnotetext{
${ }^{4}$ http://dados.sc.gov.br/dataset/covid-19-dados-anonimizados-de-casos-confirmados

${ }^{5}$ Os painéis podem ser acessados no site http://www.coronavirus.sc.gov.br/ navegando pelos itens "Transparência" e "Painéis" no menu principal.
} 
operacional e estratégico na Diretoria de Vigilância Epidemiológica (DIVE) da Secretaria de Estado da Saúde.

O Conjunto de Dados Abertos de Casos Confirmados entrega os dados de casos confirmados anonimizados em sua menor granularidade. O conjunto apresenta todas as informações relevantes sobre cada caso (Dicionário de Dados Casos Confirmados COVID-19 Dados Abertos SC, 2021) e serve principalmente aos interesses da imprensa e da comunidade científica, o que se configura como uma das formas de reconhecer o sentido no conteúdo e disponibilizá-lo a partir de uma abordagem do design da informação, conforme orienta Jorente (2015); ideia, esta, que se aplica também aos artefatos gráficos.

O Painel de Casos e Óbitos entrega informações relevantes de forma gráfica, de acordo com Petterson (2003). A aba principal apresenta dados gerais, um mapa com a concentração de casos, curvas de crescimento de casos e óbitos, listagem dos municípios com maiores contagens de casos e óbitos e ocorrências por gênero e faixa etária.

Figura 3: Painel de Casos e Óbitos, aba principal. Fonte: http://www.coronavirus.sc.gov.br/

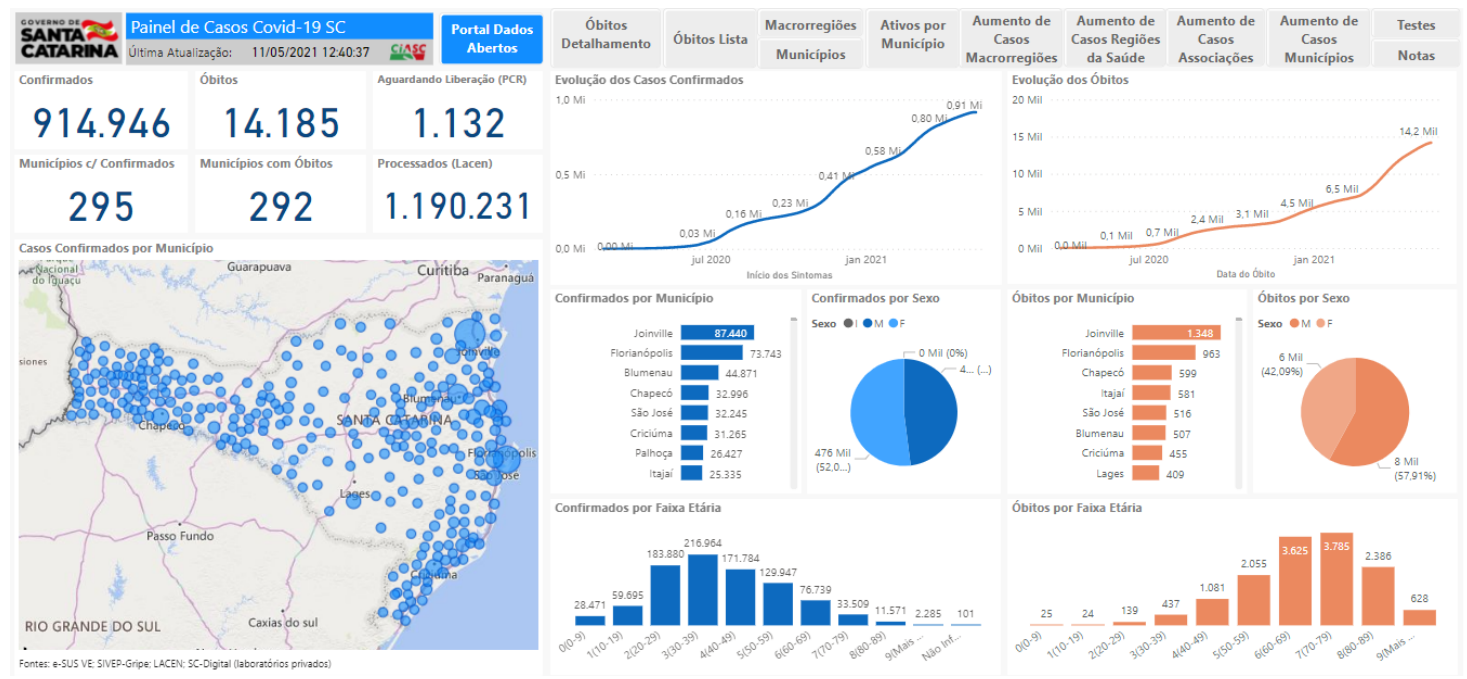

Na barra superior é possível navegar para Conjunto de Dados Abertos de Casos Confirmados e para outras abas do painel que apresentam outras informações, detalhes sobre casos e óbitos, visões regionalizadas por macrorregião administrativa e regiões de saúde e informações sobre a distribuição de testes.

O painel traz também notas explicativas para melhor compreensão da metodologia e interpretação das informações apresentadas. 
Figura 3: Painel de Casos e Óbitos, aba de testagem. Fonte: http://www.coronavirus.sc.gov.br/

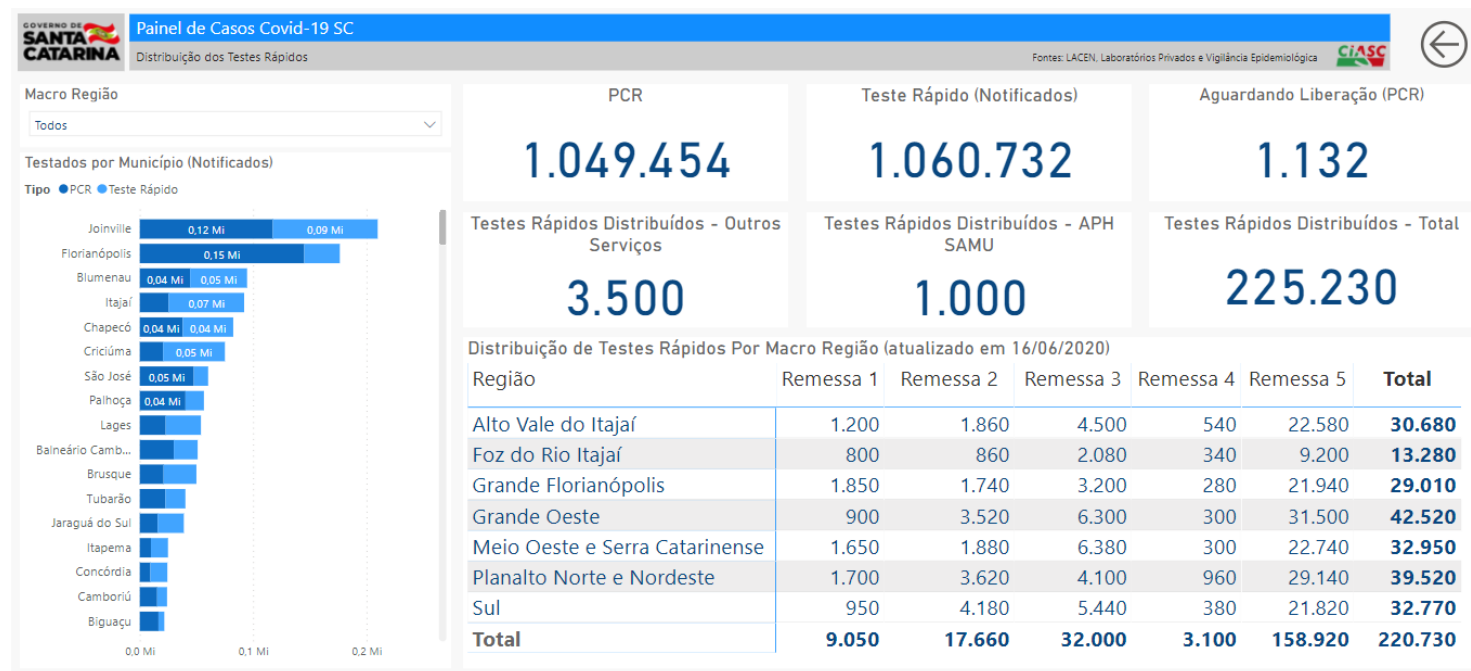

Destacam-se, a título de ilustração, a aba que apresenta dados de testagem, indicando a quantidade de testes rápidos e laboratoriais distribuídos por região e município e a que apresenta o detalhamento dos óbitos, com estatísticas da incidência de comorbidades, sintomas e taxa de letalidade.

Figura 4: Painel de Casos e Óbitos, aba de detalhamento de óbitos. Fonte: http://www.coronavirus.sc.gov.br/

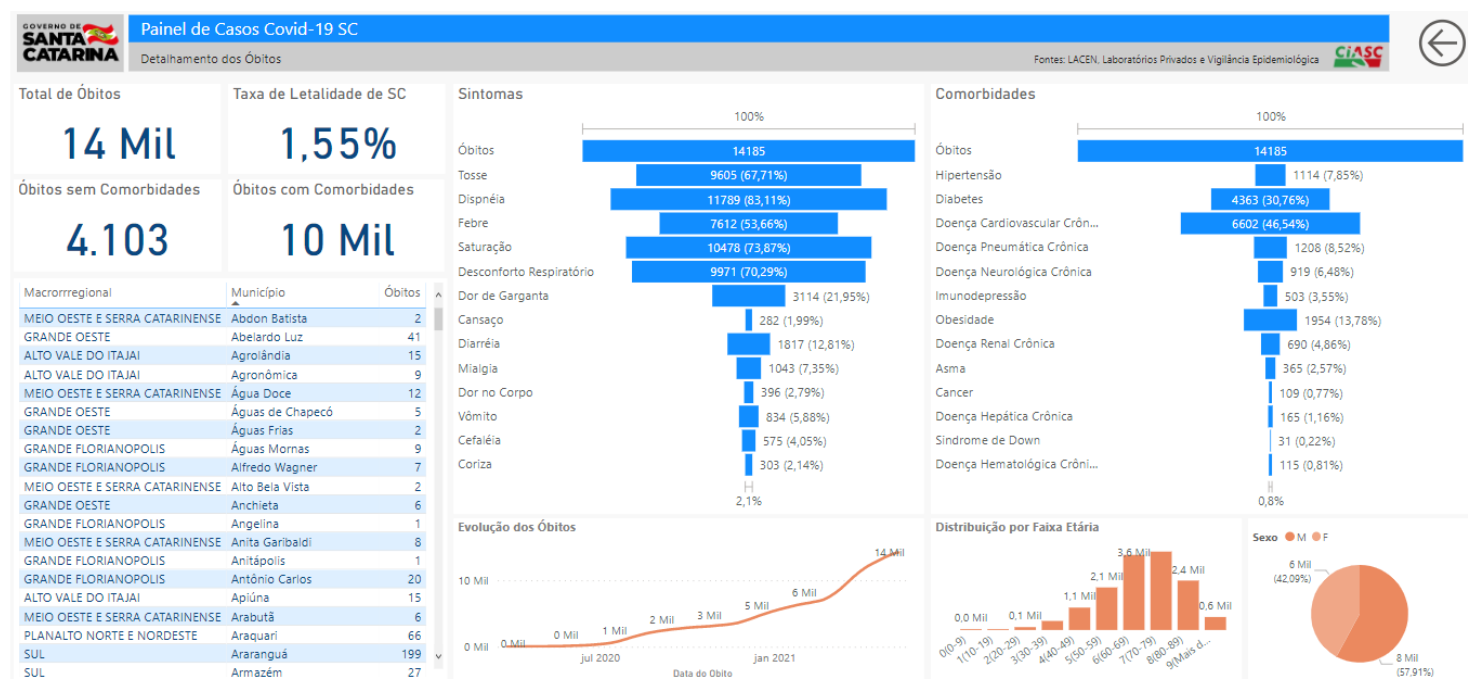

O Painel de Monitoramento Regional apresenta visualizações das informações focadas na gestão epidemiológica, na forma de indicadores e projeções. É usado pelas secretarias municipais, dentre outros interessados, para tomada de decisões estratégicas.

Os mesmos dados são usados na composição de matrizes de risco e podem ser auditados pelos gestores municipais no painel. Destacam-se a aba principal e a aba de infectantes que apresenta na forma de gráfico o número provável de agentes transmissores do vírus causador da COVID-19 (Wang et al., 2020) na linha do tempo. 
Figura 5: Painel de Monitoramento Regional, aba de infectantes. Fonte: http://www.coronavirus.sc.gov.br/

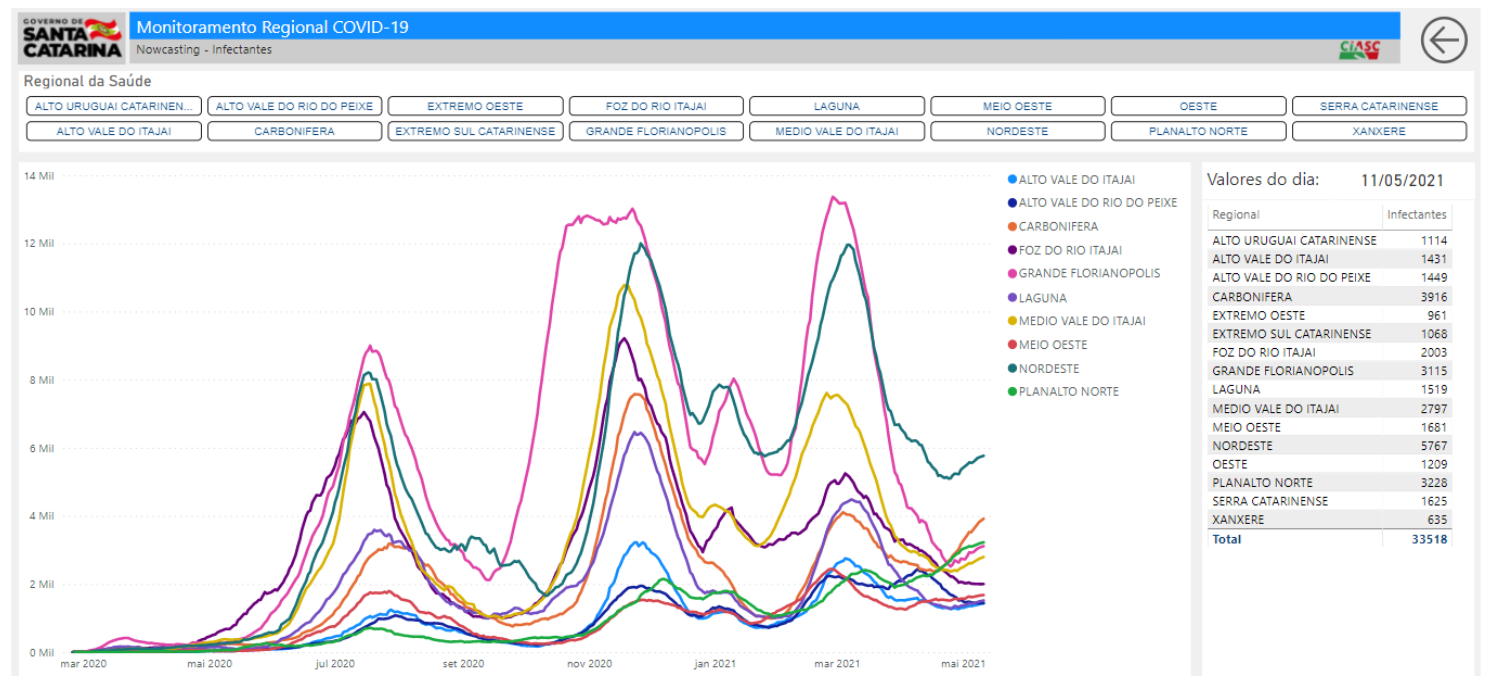

\section{Considerações Finais}

O presente trabalho descreve como a estruturação de dados orientado por um modelo adaptado de design da informação pode facilitar a organização dos dados e o entendimento de seu conteúdo desde a camada mais densa (dados brutos) até a arquitetura da informação a ser disponibilizada em um artefato gráfico.

O modelo levou a uma organização do trabalho em camadas, definidas por planos, orientados ao atendimento dos requisitos do projeto, facilitando a organização e disponibilização dos dados para subsequente compreensão e construção de conhecimento.

No entanto, vale ressaltar que este artigo não se propõe a discutir o design do artefato gráfico, tendo como foco demonstrar como um modelo de design da informação pode ser incorporado às atividades de estruturação de dados, simplificando sua compreensão enquanto conteúdo para que possa ser disponibilizado, acessado e compartilhado.

O modelo aplicado às camadas de dados proporcionou melhor visualização do contexto por parte da equipe em todas as etapas. Como consequência, a organização dos dados permitiu a compreensão das informações a serem representadas visualmente pela equipe de design, uma vez que as necessidades a serem atendidas exigiam dos artefatos gráficos apresentações diversas que só foram possíveis através dos processos de estruturação realizados nas etapas anteriores. O processo ainda gerou ganhos sinérgicos, traduzidos em um design claro e objetivo, apesar da complexidade do tema e da quantidade de informação representada nos artefatos.

O modelo proposto por Garrett (2011) mostra-se, portanto, adequado para a estruturação de dados para o design da informação. Conclui-se que é possível e necessário compreender o potencial da estruturação de dados como parte do processo de design da informação considerando a carência observada na literatura - a fim de obter opções mais diversas e completas para sua representação gráfica, além de torná-lo mais acessível, compreensível, comunicativo e organizado. Contribui-se assim, para a otimização dos resultados, garantindo 
que as necessidades dos usuários (mapeadas nos planos mais abstratos do modelo) estejam em evidência em cada passo do projeto, até a entrega da interface final.

\section{Referências}

Barros, J. A. A. (2004). Gerenciamento e uso da informação aplicada na área de Segurança Pública do Estado de Santa Catarina: Um estudo de caso no Ciasc. 106. Recuperado de https://repositorio.ufsc.br/handle/123456789/87675

Christensen, T., \& Lægreid, P. (2020). Balancing Governance Capacity and Legitimacy: How the Norwegian Government Handled the COVID-19 Crisis as a High Performer. Public Administration Review, 80(5), 774-779. Recuperado de https://doi.org/10.1111/puar.13241

Colombo, C. (2006). Innovación democrática y TIC, ¿hacia una democracia participativa? Revista de los Estudios de Derecho y Ciencia Política de la UOC, 3, 13. http://consad.org.br/wp-content/uploads/2016/06/BC-Governo-Eletr\%C3\%B4nico-01.pdf

COVID-19-Casos Confirmados-Dicionario de Dados Casos Confirmados COVID-19-Dados Abertos SC. (2021, maio 12). http://dados.sc.gov.br/dataset/covid-19-dados-anonimizadosde-casos-confirmados/resource/2128b7d4-7799-4306-ba47-4fcbb7c197f2

Darós, L. L., Stadnick, K. T., Biz, A. A., Damonin, M. A., \& Borgert, A. (2005). A contribuição de uma ferramenta de business intelligence na gestão de custos: $A$ experiência do Estado de Santa Catarina. Anais do Congresso Brasileiro de Custos - ABC, $O(0)$, Article 0. https://anaiscbc.emnuvens.com.br/anais/article/view/1974

Duan, H. K., Hu, H., Vasarhelyi, M., Rosa, F. S., \& Lyrio, M. V. L. ([s.d.]). Open Government Data (OGD) driven decision aid: A predictive model to monitor COVID-19 and support decisions in a Brazilian State. 25.

Garrett, J. J. (2011). The elements of user experience: User-centered design for the Web and beyond (2nd ed). New Riders.

Goldman, A., Kon, F., Pereira Junior, F., Polato, I., \& Pereira, R. de F. (2012). Apache hadoop: conceitos teóricos e práticos, evolução e novas possibilidades. In Anais. Porto Alegre: SBC. Recuperado de http://www.lbd.dcc.ufmg.br/colecoes/jai/2012/003.pdf

Nacional, I. (2021, maio 11). PORTARIA N 264, DE 17 DE FEVEREIRO DE 2020—DOU Imprensa Nacional. https://www.in.gov.br/web/dou

Katz, J. (2012). Designing Information: Human Factors and Common Sense in Information Design. John Wiley \& Sons, Inc.

Lægreid, P., \& Rykkja, L. H. (Orgs.). (2018). Societal Security and Crisis Management: Governance Capacity and Legitimacy (1st ed.). Palgrave Macmillan.

Pettersson, R. (2003). Information design: An introduction. Benjamins.

R: The R Project for Statistical Computing. (2021, maio 11). R: The R Project for Statistical Computing. https://www.r-project.org/

Teixeira, J. M. (2019). Gestão Visual de Projetos: Utilizando a informação para inovar. Alta Books Editora. 
Wang, Y., Xu, C., Yao, S., \& Zhao, Y. (2020). Forecasting the epidemiological trends of COVID19 prevalence and mortality using the advanced $\alpha$-Sutte Indicator. Epidemiology \& Infection, 148. https://doi.org/10.1017/S095026882000237X

\section{Sobre o(a/s) autor(a/es)}

Jefferson L. Velasco, BEL, UNISUL <jeffvelasco.crm@gmail.com> Helouíse H. G. Viola, MSC, UDESC, Brasil <helo.hellen@gmail.com> Israel A. Braglia, PHD, UFSC, Brasil <israelbraglia@gmail.com> Júlio M. Teixeira, PHD, UFSC, Brasil <julio.teixeira@ufsc.br> 